\title{
Giambattista Casti traducido por un cesante anónimo: reflexiones en torno a su identidad
}

\author{
Marcial CARRASCOSA ORTEGA* \\ Universidad Complutense de Madrid
}

Recibido: $13 / 03 / 2011$

Aceptado: 27/04/2011

\section{RESUMEN}

El objeto de este trabajo se centra en la identificación de un traductor anónimo español, que se presenta entre los siglos XVIII y XIX con el seudónimo de «Un Cesante», del que sabemos que tradujo parcialmente la obra Gli Animali parlanti del abate italiano Giambattista Casti (1721-1803), poema de zooépica satírico-burlesca en sextinas que gozó de una amplia difusión en la Europa decimonónica. Tras localizar y describir dicha traducción, a la que el anónimo añadió una parte original -textos hasta ahora no estudiados-, el artículo identifica al traductor/autor y detecta las razones por las que trató de mantener, a toda costa, su anonimato.

Palabras clave: Gli Animali parlanti, Los Animales parlantes, Casti, Cesante, Antero Benito Núñez.

\section{Giambattista Casti translated by an anonymous 'Cesante': Reflections about his identity.}

\begin{abstract}
The aim of this research is to identify the anonymous Spanish translator, located between the 18 th and 19th centuries, who used «Un Cesante» as pseudonym, and who is known for the partial translation of the work Gli Animali Parlanti, a poem written by the Italian abbé Giambattista Casti (1721-1803),. It is a poem about a satirical-burlesque zoo-epic subject matter written in sestinas that had a wide diffusion in the 19th century Europe. After localizing and
\end{abstract}

* Marcial Carrascosa Ortega. Dpto. de Filología Italiana, Facultad de Filología (Edificio D). Universidad Complutense de Madrid. Ciudad Universitaria s/n, 28040 Madrid. marcial.carrascosa@yahoo.es 
describing that translation, in which the anonymous translator added one original part -not studied texts until now- the article identifies the translator/author who tried to keep his anonymity by any means.

Key words: Gli Animali parlanti, Los Animales parlantes, Casti, Cesante, Antero Benito Núñez.

«La esperanza hace que el náufrago agite sus brazos en medio de las aguas, aún cuando no vea tierra por ningún lado»

Ovidio: Pónticas, Libro I, 6

\section{INTRODUCCIÓN}

Hay algunos misterios que, por diversas razones, permanecen ocultos durante años, décadas o incluso siglos. Algunas veces, sin embargo, se consiguen desvelar como consecuencia de arduas investigaciones, otras veces por puro azar o, incluso, por la combinación de ambos factores.

Cuando se aborda el estudio de autores relevantes, suele decirse, con cierta razón, que de ellos está casi todo dicho, mientras que cuando se trabaja con autores menos conocidos, existen más posibilidades de rastrear y encontrar textos inéditos o descubrir datos que han permanecido ocultos durante décadas o centurias. A este segundo grupo pertenece Giambattista Casti (1721-1803), un polifacético abate romano, literato culto, compositor de libretos, tertuliano ameno y hábil versificador $^{1}$. Su condición de viajero y asiduo acompañante de diplomáticos en las distintas embajadas austriacas le facilitó innumerables experiencias y relaciones sociales en las principales Cortes europeas y, tanto en vida como en los años posteriores a su muerte, gozó de mucha fama y prestigio. No obstante, y de manera injusta, la crítica -especialmente la italiana- lo ha mantenido prácticamente relegado desde mediados del siglo XIX hasta hace apenas unas décadas, debido en gran parte a que desde muy joven siempre se vio 'perseguido' por su fama de libertino y su carácter polémico, siendo uno de los máximos exponentes de la literatura licenciosa del Settecento. Su producción literaria, casi toda en verso, tiene un marcado tono satírico y jocoso y en ella el abate italiano, haciendo uso de una fina ironía, arremete contra todos los estamentos sociales ${ }^{2}$. Las tres principales obras de Casti -el Poema tarta-

1 En 1792 el emperador austriaco Francisco II lo nombró Poeta Cesáreo, cargo de gran relevancia y prestigio, en el que había sido precedido por otros nombres ilustres en el mundo musical vienés como Pietro Metastasio o Lorenzo Da Ponte.

2 Casti denuncia en sus obras los abusos y vicios del clero, de los nobles y de los monarcas y emperadores que hacen un uso despótico del gobierno, así como también arremete contra el servilismo y la sumisión del pueblo, que vive casi en régimen de esclavitud. La pertinaz defensa de sus ideas, llevada a veces hasta las máximas consecuencias, le ocasionó numerosos disgustos, así como la expulsión de algunas Cortes europeas. 
$\mathrm{ro}^{3}$, las Novelle galanti ${ }^{4}$ y Gli Animali parlanti- gozaron de un enorme éxito entre el público, como lo demuestra el gran número de ediciones existentes, si bien muchas de ellas fueron impresas alla macchia, sin ningún control y con la desaprobación del mismo autor ${ }^{5}$.

Centrándome en Gli Animali parlanti, a cuya difusión en España llevo dedicándome algún tiempo, debo decir que se trata de un largo poema zooépico satírico-burlesco que consta de veintiséis cantos en sextinas, además de uno adicional titulado "Origine dell'Opera», que debería haber funcionado como prólogo. Esta era la intención de Casti cuando lo publicó en París en 1802, aunque por diversos motivos editoriales el abate tuvo que llevar a cabo una serie de modificaciones y posponerlo al final del poema.

La obra plantea una crítica mordaz, con un marcado carácter político y social. Bajo la apariencia inofensiva de una historia protagonizada por animales, el autor denuncia los abusos de las monarquías absolutas y del clero, además de llevar a cabo una fuerte sátira contra la hipocresía reinante en la Francia post-revolucionaria. Y no olvidemos que París era su lugar de residencia en esos años.

El poema castiano, desde su publicación, gozó de un enorme éxito y tuvo una extraordinaria difusión. Solo en ese año de 1802, algunos impresores llegaron a tirar hasta cinco ediciones. Se sucedieron además muchas clandestinas no autorizadas por el autor, en cuya portada figuraban nombres de impresores, fechas y lugares de edición falsos ${ }^{6}$. La obra, como es obvio, pronto resultó 'molesta' y pasó a engrosar, como ya lo habían hecho las Novelle galanti, el Index librorum prohibitorum ${ }^{7}$, lo que

3 El Poema tartaro (Italia [Milano], 1797), escrito en octavas, es una crítica feroz contra la figura de la Emperatriz de Rusia Catalina II, a la que Casti juzga como uno de los grandes males que asolan Europa, tanto por su carácter y su hipocresía, como por su política expansionista. Entre otros asuntos, Casti no ve con buenos ojos el acercamiento político que lleva a cabo el Emperador austriaco José II con respecto a Rusia, lo que le vale la expulsión de la Corte de Viena y su posterior 'exilio voluntario' a París en 1798.

${ }^{4}$ Las Novelle galanti (Parigi, Anno IX [1801-1802]), también escritas en octavas, reúnen 48 relatos a modo de cuentos, de tono ameno y distraído, protagonizadas por personajes típicos de la sociedad italiana y europea del momento. En algunas se emplean términos que pueden entenderse con un doble sentido e incluyen a miembros del clero, hecho que contribuyó a que desde el principio se tildasen de obscenas. Casti las fue componiendo a lo largo del último cuarto del siglo XVIII y se fueron publicando en varias fases, constando las primeras ediciones de dieciocho novelle, hasta la aparición de las cuarenta y ocho en la edición parisina.

5 En el caso de las Novelle galanti, la proliferación de ediciones clandestinas -algunas de ellas aparecen modificadas con relatos inventados, todavía más subidos de tono que los del propio Casti-, obligó al autor a realizar una «Protesta» formal en verso - que encabezará las ediciones sucesivas-, en la que denuncia este asunto y además señala los títulos de los cuentos que sí son suyos. La temática de esta obra contribuyó a su rápida inclusión en el Index librorum prohibitorum (Decreto de 2 de julio de 1804).

${ }^{6}$ No deja de resultar curioso que, incluso, se recurre a lugares exóticos. En relación con esto, encontramos, por ejemplo, una edición de Gli Animali parlanti en cuya portada dice «A Pe-King, regnante KienLong, 1799». Para la consulta de lugares de imprenta falsos o inventados, resulta de gran utilidad el Dizionario di luoghi di stampa falsi, inventati o supposti in opere di autori e traduttori italiani de Marino Parenti (1951). A pesar de su gran interés, y en relación con las obras no solo de Casti sino de autores más conocidos, la obra de Parenti necesitaría una profunda revisión, puesto que no aparecen reflejadas algunas ediciones que tuvieron gran difusión. Sirva como ejemplo que no se menciona la que cito en esta misma nota.

7 Véase en Diario de Madrid (14-VII-1805), en el apartado de [Libros] prohibidos aun para los que tienen licencia, donde aparece entre los libros más 'peligrosos', nada menos que en segundo lugar: «Nos los Inquisidores apostólicos contra la herética pravedad y apostasía por Autoridad Apostólica, Real y Ordinaria. 
propició, si cabe, un mayor interés en el lector culto. Al principio la obra se difundió en italiano, aunque pasada apenas una década desde su publicación, comenzaron a sucederse las primeras traducciones a las principales lenguas europeas ${ }^{8}$.

Por lo que respecta al panorama español, además de contar con la traducción más temprana de cuantas se imprimieron en Europa ${ }^{9}$, disponemos también de varias traducciones castellanas más del poema de Casti, con un abanico de posibilidades: unas parciales y otras completas, bien en prosa bien en verso, tanto publicadas como inéditas ${ }^{10}$; e incluso se tiene noticia de otras en castellano o catalán, de cuya existencia hay testimonio pero de las que actualmente se desconoce su paradero ${ }^{11}$.

[...] Hacemos saber, que a nuestra noticia ha llegado haberse escrito, impreso o divulgado varios libros, impresos y papeles, que pueden ocasionar la ruina espiritual de vuestras almas, los quales mandamos prohibir y expurgar respectivamente, como aquí se expresa, y son los siguientes: Prohibidos aun para los que tienen licencia [...] 2. Gli Animali Parlanti, Poema epico diviso en [sic] ventisei canti di Giambatista [sic] Casti, vi sono in fine aggiunti quattro Apologhi del medesimo Autore, non appartenenti al Poema, 3 tomos en $8 .^{\circ}$, impresos en París en 1802: por ser obra sumamente impía, mordaz y sediciosa, y estar llena de proposiciones obscenas e injuriosas a las Supremas Potestades, a los Sumos Pontífices, y con especialidad contra los Estados Monárquicos» (p. 57).

8 A este respecto -sin detenerme aún en el ámbito español, que se tratará posteriormente- hago mención de las traducciones publicadas de las que tengo noticia: al inglés, The Court of Beasts (1816), más conocida por una segunda edición que lleva por título The Court and Parliament of Beasts (1819); al alemán, Die redenden Thiere (1817); al francés, Les Animaux parlans (1818 en prosa y 1819 en verso); al portugués, Os animaes fallantes (1835).

${ }_{9}^{9}$ Esta traducción, - en verso, aunque no en sextinas- a cargo del diputado liberal Francisco Rodríguez de Ledesma y de la que solo se conocen los dos primeros cantos, apareció publicada en Madrid bajo el título de Los Animales hablando en 1813.

${ }^{10}$ De especial interés resulta el artículo de María de las Nieves Muñiz Muñiz (2003) en el que aborda el panorama de las primeras traducciones españolas conservadas y localizadas de Gli animali parlanti. La misma autora se ocupa en otro artículo (Muñiz 2005) de la primera y única traducción completa de Gli Animali parlanti impresa en España, publicada en prosa en 1840. En relación con la recepción de Casti en España, puede verse también el reciente trabajo de Ángeles Arce (2009: 186-187).

${ }_{11}$ De entre todas estas traducciones inéditas cuyo paradero desconocemos pero de las que se tiene noticia que existieron, podríamos destacar tres: una en castellano, al parecer completa, que llevó a cabo el historiador de la Inquisición Juan Antonio Llorente (1756-1823), entre los años de 1812 y 1813, tal y como nos cuenta en su Autobiografia (Llorente 1982: 121-123). En esta obra, publicada en 1818 en París con el título de Noticia biográfica de D. Juan Antonio Llorente, o memorias para la historia de su vida escritas por él mismo, apenas cinco años antes de su fallecimiento, el autor asegura que aún la conserva, a falta de someterla a una última revisión. La segunda traducción inédita que hay que destacar, de la que nada se sabe, también redactada en castellano, en verso y sin poder precisar si es de todo el texto o solo de una parte, era la que vio D. Dionisio Solís en 1821, llevada a cabo por un abogado que él trataba y que no se imprimió «por lo pesado de su estilo y la poca fluidez de la versificación». El dato nos lo aporta D. Pascual Asensio en una carta fechada el 31 de enero de 1872, que había enviado a D. Juan Eugenio Hartzenbusch, a la sazón Director de la Biblioteca Nacional de Madrid, con motivo de la donación a esta institución de un manuscrito anónimo que contiene la traducción española, casi completa, de las Novelle galanti de Casti, faltando solo cinco de las cuarenta y ocho novelle que componen la obra original. Dicha carta antecede al manuscrito, que actualmente está encuadernado en dos volúmenes (Mss. 4083 - 4084). La tercera traducción inédita digna de mención y cuyo paradero se desconoce es la que llevó a cabo D. Miguel Antón Martí (†1864), en catalán, en el primer tercio del siglo XIX. Aunque existen varias fuentes que la citan, tomo este dato de D. Juan Luis Estelrich, que recibió una carta de D. Marcelino Menéndez Pelayo el 6 de enero de 1889 en la que le decía: «Según creo existe una [traducción] catalana inédita de D. Miguel Antón Martí de quien te dará noticia [Antonio] Rubió». Una vez establecido el contacto, el mismo Rubió escribió otra carta a Estelrich el 30 de enero de 1889, en la que le confirmó que esta traducción «fue leída en una sesión de la Academia de Buenas Letras; [...] No se publicó jamás y quien puede darte de ella más noticias es Cayetano Cornet y Mas, pariente del traductor, que guarda sus manuscritos» (Estelrich 1889: 789). 
Entre todas ellas se encuentra una curiosa traducción parcial, objeto de este estudio, que apareció publicada de forma anónima 'por entregas' y en cuadernillos sueltos bajo el seudónimo de «Un Cesante». En 1822 su autor dio a conocer los dos primeros cantos, que son traducción directa de Gli Animali parlanti, con el mismo número de sextinas ${ }^{12}$ que el original. A continuación de la traducción de estos y siguiendo el orden de la paginación anterior, se añade un tercer canto titulado $L a$ Amnistía, canto tercero de los Animales parlantes, publicado también en ese mismo año, pero que no pertenece a Casti, sino al «Cesante», que con la intención de diferenciarlo de lo hecho hasta entonces lo denomina «intercalar» ${ }^{13}$. El éxito de este canto de La Amnistía, propició al año siguiente, en 1823, una segunda edición del mismo, esta vez muy aumentada, que bajo el título de La Amnistía del León pasó a tener cuatro cantos. La nueva versión, que ya solo por su extensión puede considerarse una obra independiente propiamente dicha, incluye un primer canto que se corresponde con el anterior de La Amnistía, aunque revisado y con variantes, y otros tres completamente nuevos. Si bien se hacen frecuentes llamadas a los dos cantos traducidos, el autor ha eliminado del título la referencia a Los Animales parlantes y, al dotar al 'nuevo' poema de paginación propia, muestra su intención de 'originalidad'.

Pese a su 'rareza', este trabajo del «Cesante» era conocido en la España de la segunda mitad del siglo XIX, y sirva como ejemplo de ello el fragmento de una carta que escribe Menéndez Pelayo a Gumersindo Laverde, fechada el 12 de octubre de 1875, en la que da algunas noticias sobre los traductores españoles de Casti y dice:

Existe además una traducción en verso de los primeros Cantos, publicada, durante la época constitucional del 20 al 23, en forma de cuadernos sueltos por un escritor, cuyo pseudónimo era El Cesante, Rayón ${ }^{14}$ la tiene (Menéndez Pelayo 1982: 334-335).

Precisamente, las duras críticas lanzadas por D. Marcelino contra el abate Casti han debido de influir de forma evidente para que el autor italiano, tan en boga enton-

12 En cuanto al empleo de la «sextina», por tratarse de un término que guarda cierta ambigüedad, conviene hacer una aclaración al respecto: en Gli Animali parlanti, Casti hace uso de la «sextina real»o «sexta rima»-en Italia, también conocida como sestina narrativa-, una estrofa de tipo isométrico, con rima consonante, en endecasílabos, que obedece al esquema $\mathrm{ABABCC}$; en ningún caso debe confundirse con la composición poética del mismo nombre, que se desarrolló en centurias anteriores, sobre todo, desde la época medieval - por Dante y Petrarca, entre otros- hasta finales del siglo XVI.

${ }^{13}$ Resulta imprescindible aclarar que en este caso «intercalar» no tiene la función de verbo transitivo en su modo infinitivo, sino que funciona como adjetivo. Al respecto de este término, dice el Diccionario de la R.A.E. en su primera acepción: «intercalar ${ }^{1}$. (Del lat. intercalâris). 1. adj. Interpuesto, injerido». Se trata, por tanto, de una intromisión del traductor, motivada indudablemente por los avatares políticos y sociales acaecidos en España durante el Trienio Liberal, justamente cuando el «Cesante» está llevando a cabo su versión. En este mismo trabajo también se verá que el traductor va a justificar esta injerencia amparándose en que el ejercicio de traducción le ha resultado bastante más trabajoso que el de composición propia además de servirle «de desenfado».

${ }^{14}$ No he podido constatar si Menéndez Pelayo se refiere a su amigo personal D. Damián Menéndez Rayón († 1883), archivero del Ministerio de Hacienda, además de periodista y notable intelectual o, por el contrario, se trata de D. José Sancho Rayón (1836-1900), gran erudito con el que también mantuvo trato y correspondencia, y que por su condición de reconocido bibliófilo bien pudiera encajar mejor en este contexto. 
ces, pese al puritanismo decimonónico, haya pasado desapercibido en España durante bastantes décadas ${ }^{15}$.

\section{EL TEXTO DEL «CESANTE»}

Tal y como se adelantó, el texto español no apareció de forma homogénea, sino a través de cuadernillos sueltos que coinciden con los respectivos cantos. El traductor quizás supuso que una publicación por entregas podía resultar más exitosa para un público ávido de nuevas lecturas, sobre todo si incluían temas socio-políticos tan comprometidos como los que se abordaban en el poema italiano. Por otra parte, tratándose de una obra tan voluminosa de 3184 sextinas, si su plan editorial no gozaba del éxito esperado, siempre podría interrumpir el proyecto y al menos la empresa no se vería abocada a perder dinero.

Sin embargo, tradicionalmente este tipo de publicación ha tenido una serie de desventajas frente a los textos editados de manera unitaria, principalmente por dos motivos: uno, que sus condiciones de conservación, en muchos casos, no han sido las más idóneas - muchas veces simplemente por carecer de una sólida encuadernación- $\mathrm{y}$, otro, su fácil extravío, que ha propiciado que las colecciones aparezcan incompletas. Si nos atenemos a lo que hasta aquí se ha expuesto, podríamos pensar que desde el punto de vista del traductor, su elección fue la más sensata, aunque resultase menos cómoda para el lector. Sin embargo, objetivamente, las circunstancias políticas del momento propiciaron que, aunque incompleto, hoy dispongamos de un texto que, con seguridad no hubiera visto la luz.

Si tenemos en cuenta la extensión del poema original, la traducción le hubiera llevado mucho tiempo, con la consiguiente demora de publicación, por lo que en apenas un año, al «Cesante» le hubiesen sorprendido tanto el regreso de Fernando VII al poder, como el inicio de la represiva Década ominosa. Estos acontecimientos políticos hubiesen propiciado que hoy, probablemente, no tuviésemos esta versión, como tampoco sabemos si se tradujo o no el resto del poema o si todavía se conserva, de forma manuscrita en los fondos de alguna institución, en manos de un particular, o incluso en el extranjero.

Al margen de conjeturas y ateniéndonos al texto que sí tenemos, vemos que cada uno de los cantos se presenta con su propia portada y su particular estructura. En cuanto a su descripción, me limitaré a señalar el contenido completo de las portadas y a proporcionar información de carácter general, sin analizar en detalle, salvo casos muy puntuales, aspectos relevantes de la traducción, de cuyo análisis me ocuparé en un futuro estudio.

Para la realización de este trabajo me sirvo de los ejemplares de la Biblioteca Nacional de España (BNE) y de la Biblioteca Menéndez Pelayo de Santander

15 En España no se han vuelto a publicar nuevos estudios sobre la obra y la controvertida figura de Casti hasta época reciente, donde destacan principalmente las contribuciones de Ángeles Arce, Nieves Muñiz y Antonio Becerra Bolaños. 
(BMP) que, como se verá, se complementan en pasajes puntuales ${ }^{16}$. La reproducción de los textos es absolutamente fiel, sin modernizar grafías ni acentuación.

Canto I

Los | Animales PaRlantes | DE CASTI. | En el mismo género y número | de versos españoles que el ori- | ginal italiano. | POR UN CESANTE. || MADRID: | Imprenta Calle de la Greda: por su regente | D. Cosme Martinez: 1822. | Se hallará en la librería de Cruz, frente las $\mid$ gradas de S. Felipe, á 4 reales.

El fascículo consta de 54 páginas. Tras la portada (p. 1) hay un «Semiprólogo» (p. 2) y a continuación el «Prólogo formal é indispensable» (pp. 3-5), donde el traductor español anónimo da cuenta de la traducción publicada en 1813, en verso, por Don Francisco Rodríguez de Ledesma, abogado de la Corte y diputado en la anterior legislatura, así como de otras dos versiones: por una parte, una que él ha visto y que está dispuesta para la imprenta y, por otra, una segunda que ha oído que en ese momento se está imprimiendo ${ }^{17}$. A continuación, deja clara su intención de publicar por entregas y añade:

Malos, malísimos han de ser mis versos, y mala malísima mi traduccion, cuando no se saquen los costos: tal es el mérito de Casti. Pero yo no me contento con no perder; es preciso ganar. Si el éxito pues, de mi primer canto corresponde á mis deseos, se continuará la impresion en el mismo papel, tamaño y $\operatorname{carácter}^{18}$ (p. 3).

Posteriormente el traductor español anónimo explica las diferentes formas de gobierno tratadas por Casti y hace una defensa del italiano frente a los que lo criticaban.

Tras estos prolegómenos, el texto propiamente dicho, en edición bilingüe italiano-español, comienza en las páginas 6 y $7^{19}$, ocupando el italiano las páginas del lado izquierdo y el español las del derecho. Se traducen las 108 sextinas de que consta el original castiano y como complemento a la traducción aparecen, a menudo, notas aclaratorias a pie de página, que resultan de gran interés ${ }^{20}$.

16 A continuación se señalan los ejemplares consultados y sus correspondientes signaturas de localización: Canto I, BNE Signaturas 1/23165 y VC/12603/43; Canto II, BNE Signatura 1/23165; La Amnistía [Canto III «intercalar»], BNE Signaturas VC/633/28 y VE/697/34; La Amnistía del León, BNE Signatura VE/697/33 y BMP Signatura 16257.

17 Estas dos traducciones que cita el «Cesante» aparte de la de Rodríguez de Ledesma, bien pudieran ser la del historiador de la Inquisición Juan Antonio Llorente y la del abogado al que trataba don Dionisio Solís, que anteriormente citábamos entre aquellas que conocemos solo por menciones y cuyo paradero se ignora.

18 No está de más apuntar que la impresión es bastante limpia y el papel empleado es de buena calidad. Como asegura el traductor, todos los cuadernillos tendrían las mismas dimensiones, esto es 19 x $12 \mathrm{~cm}$.

19 El ejemplar de la Biblioteca Nacional de España con signatura 1/23165 carece de estas dos páginas. No presenta signos de mutilación, lo que hace pensar que las páginas referidas han faltado si no desde siempre, al menos desde el momento en que se encuadernó. En cambio, en el ejemplar con signatura VC/12603/43 puede consultarse el texto completo.

20 Entre estas notas, las encontramos de dos tipos: unas son explicativas y apuntan al pensamiento político de Casti, mientras que las otras tienen que ver con aspectos de la traducción. Entre las primeras podría- 
Por último, en la página 54, con la que se pone fin al volumen, aparece la fe de «erratas».

Esta primera entrega, correspondiente al Canto I, salió a la luz a principios del mes de mayo de $1822^{21}$. Resulta curioso que en 1852 se volverá a publicar, aunque muy fragmentado, por iniciativa del periodista y crítico literario siciliano Salvatore Costanzo en su versión castellana de Storia di cento anni 1750-1850 de Cesare Cantù ${ }^{22}$.

\section{Canto II}

Segundo CANTo | De los | Animales Parlantes | En el mismo género y número | de versos españoles que el ori- | ginal italiano. || MADRID: | Imprenta calle de la Greda: por su regente | D. Cosme Martinez: 1822. | Se hallará en la librería de Cruz, frente las $\mid$ gradas de S. Felipe, á 4 reales.

El volumen, que consta de 47 páginas, continúa con la paginación correlativa respecto al canto anterior (pp. 1-54), ocupando la portada la página 55 -aunque no está numerada- y finalizando el texto traducido en la página 101 -la 102, en blanco-. Al igual que en el Canto I, se traducen todas las sextinas del original, que en este caso también son 108 .

Este canto segundo podía adquirirse junto con el primero o bien independiente si ya se disponía del anterior. El éxito de lectores cosechado por el Canto I hizo que apenas en un mes saliese esta segunda entrega ${ }^{23}$.

mos citar por ejemplo la del último endecasílabo de la sextina 26 («Nada hay en él de malo, bueno todo (*)»), donde en alusión al gobierno monárquico dice la nota: «(*) Lo que dice Casti, irónicamente lo dice Volnei [Conde de, 1757-1820] con mucha seriedad y seguramente Casti y Volnei no pueden estar en contradiccion sobre este punto. ¿Que prueba esto? Lo que he dicho en mi prologo. Sirva esta nota para todo lo demas que pueda chocar al ignorante, ó censurar el maligno». Por otro lado, entre las notas relativas a la traducción, se puede destacar la que alude a la sextina 66, que dice: «Nadie deberá estrañar que me haya tomado alguna libertad en la traduccion de esta estrofa».

${ }^{21}$ El 11-V-1822, en el periódico político y literario El Censor, de notoria vocación afrancesada, aparece lo siguiente: «[ANUNCIO:] Los animales parlantes de Casti, traducidos al español en el mismo metro y número de versos que el original italiano. Canto $1^{\circ}$. Se hallará en la libreria de Cruz enfrente de las gradas de San Felipe, á 4 rs.: puede ir en carta.

No pudiendo dudar ya el traductor del aprecio con que se ha recibido generalmente su trabajo, esperamos que como promete no defraudará al Parnaso español de un poema tan celebrado y tan del dia, en que se han hecho familiares las voces despotismo, democracia, aristocracia ect. [sic], pudiendo decir en elogio de esta dificilisima traduccion, en que se han estrellado otros ingenios, que esta no solo conserva toda la gracia y gallardia del original, sino que hay estrofas en que el idioma español, diestramente manejado por el autor, le da un realce considerable» (Censor 1822a: 240).

${ }^{22}$ Salvatore Costanzo, en una nota, se lamenta de que Cesare Cantù apenas cite «fugazmente» la figura de Giambattista Casti y además lo haga en relación con sus obras menores. A continuación esboza una brevísima semblanza del abate dieciochesco y da cuenta de las principales traducciones españolas conocidas de Gli Animali parlanti. Por el interés que le suscita la obra del «Cesante», reproduce la portada, el semiprólogo, el prólogo y algunos pequeños grupos de sextinas del Canto I (Cantù 1852: 367-370).

${ }_{23}$ El 15-VI-1822, en el citado periódico político y literario El Censor, aparece lo siguiente: «ANUNCIO: Los animales parlantes de Casti, traducidos al español en el mismo metro que el italiano. Canto $2^{\circ}$ y $3^{\circ}$ intercalar, original, intitulado La Amnistía. Se hallará en la libreria de Cruz á cuatro reales los dos primeros cantos, y á dos reales el $3^{\circ}$. 
Al contrario que el anterior, este canto segundo no incluye una fe de «erratas» ni va enriquecido con notas críticas ${ }^{24}$; se limita únicamente a mostrar de forma paralela el texto italiano a la izquierda y la traducción castellana a su derecha, lo que podría demostrar una cierta 'prisa' por concluir el trabajo.

Pasados ya bastantes años, Juan Luis Estelrich publicó un fragmento de esta versión del Canto II, con el título de «Elección del rey de los animales cuadrúpedos», en su Antología de poetas líricos italianos (Estelrich 1889: 694-98).

\section{Canto III [《intercalar»]: La Amnistía}

Tal como ya se explicó, a partir de aquí vamos a encontrar un cambio de actitud: el hasta ahora traductor pasa a autor original con la siguiente portada:

La Amnistía. | CANTO tercero | De los | Animales Parlantes, | intercalar y original del traduc- | tor de los dos primeros. || MADRID: | Imprenta calle de la Greda: por su regente | D. Cosme Martinez: 1822. | Se hallará en la librería de Cruz, frente las $\mid$ gradas de $S$. Felipe, á 2 reales.

El folleto consta de 16 páginas, correlativas a los anteriores cantos, coincidiendo la portada con la página 103 -aunque no está numerada- y finalizando el texto en la página 118 .

Tras la portada hay un «Prólogo | para los tontos» (p. 105), que por su interés, reproduzco:

Si hubiesemos de graduar el mérito de | las obras por el trabajo que cuestan á sus | autores, deberia yo estar muy satisfecho de | de [sic] mi traduccion del famoso Casti, al paso | que desconfiadisimo de mi Canto intercalar. | Confieso que he traducido algunas estrofas | calamo currente, pero otras me ha costa- | do dias y dias; de modo, que yo no puedo $\mid$ gastar menos de un mes en cada canto de | Casti, trabajando mucho; cuando la Amnistía, | en que me he detenido solos cuatro dias, | me ha servido de desenfado. Si fuese de in- | terés hacer esta verdad palpable, no me cos- $\mid$ taria mas que divertirme otro tanto tiem- $\mid$ po. Prescindiéndo, pues, del gran mérito | de Casti, y hablando solo de mi traduccion | y mi Canto intercalar, digo que es igual el | mérito de uno y otro. Seguramente no ape- | [p. 106] lará de este fallo el señor autor de la $\mathrm{Am}$ - | nistía con toda su originalidad. |

Y ¿á que viene toda esa conversacion?|A demostrar a los tontos, que un traductor $\mid$ de verso á verso vale bien un autor original ${ }^{25}$.

Ya hemos dado noticia de esta obra anunciando el canto $1^{\circ}$, y el público ha confirmado el juicio que formamos de ella: debemos solo añadir que el mérito del canto intercalar no es inferior al de los dos traducidos» (Censor 1822b: 1600).

24 Solo se encuentra una nota en todo el Canto II y está colocada en el último endecasílabo de la sextina 107 (p. 99). Así, los dos últimos versos de dicha sextina, dicen: «Solo el Rey, solo el Rey todo lo absorve, [sic] | Todo sin él es m::: en todo el orbe ». En la nota, marcada con un asterisco (*), en obvia alusión a «m:::», leemos: «El original dice secrezione impura». Aclarado queda que la nota no es explicativa ni es crítica; el traductor la ha colocado 'delicadamente' para evitar citar de forma completa una palabra soez y de evidente tono escatológico.

${ }^{25}$ Las cursivas que aparecen en este fragmento no son mías sino que se muestran así en el texto. 
Este Canto III mantiene el uso de la sextina, con un total de 47 estrofas, pretendiendo seguir el estilo de Casti, aunque ya no se ofrece, como es obvio, en edición bilingüe. En la última página y con intención de continuidad hay una nota de erratas alusiva a la estrofa 76 del Canto II, lo que corrobora que este y el tercero vieron la luz al mismo tiempo ${ }^{26}$.

Con posterioridad y sin que pase mucho tiempo, aparecerá una segunda edición de La Amnistía, aunque con tantos añadidos, como ahora veremos, que hará difícil percibir la idea de continuidad pretendida inicialmente por el autor.

\section{La Amnistía del León}

En poco tiempo, el «Cesante» decidió revisar el texto del Canto III, que había titulado La Amnistía, pero son tantas las modificaciones que podríamos hablar, no ya de una revisión, sino de un poema con entidad propia: de un canto se pasa a cuatro; en el título desaparece la alusión a Los Animales parlantes, que pasa a denominarse La Amnistía del León; por último, la novedad más importante de esta nueva versión es la aparición de unas siglas con las que el autor trata de darnos más datos sobre su identidad. Pese a ello, la información será 'relativa', ya que el ignoto «Cesante» pasa a un no menos anónimo «A.B.D.V.B.».

La Amnistía | Del Leon. | Poema, dividido en cuatro cantos. | Por A.B.D.V.B. || Curam habe de bono nomine. | (Eccl. 41.) || MADRID: | IMPRENTA CALLE DE LA GREDA: POR D. C. MARTINEZ: | 1823. || Se vende en la librería de Cruz, frente las | gradas de S. Felipe, á 5 rs.; y con los dos | primeros cantos de Los ANIMALES PARLANTES, | á 10 rs.

El texto abarca 62 páginas, que en este caso ya no van numeradas de forma correlativa a los anteriores cantos; se evidencia así el 'cambio de intenciones' por parte del autor que, al haber aumentado tanto la extensión, inicia la paginación desde el principio ${ }^{27}$. Los cuatro cantos en que se divide, constan de $56^{28}, 67,63$ y 40 sextinas respectivamente.

Tras la portada, sigue el texto que reproducimos:

NOTA. | Como en este poema se ha- | cen llamadas muy frecuentes á | los dos cantos primeros de Los | Animales parlantes, será muy | útil tenerlos á la mano; y por | esto se han unido al poema: | vendiéndole tambien suelto pa- | ra los que tengan ya dichos | dos cantos. || También se advierte, que | el primero de La Amnistía del

26 Este hecho no hace más que evidenciar lo que se decía anteriormente, en el anuncio de prensa de $E l$ Censor (15-VI-1822) de la nota 22 del presente trabajo.

27 A este respecto, en la nota 1 de La Amnistía del León, dentro del apartado de notas finales (p. 57), dice el autor: «Habiendo tenido buena acogida mi traduccion | de los dos primeros cantos del célebre poema | de Casti, intitulado Los Animales parlantes, | pensé yo tambien echar mi cuarto á espadas, | y hacer del autor original; pero á la sombra, | ó bajo la proteccion de este poema. He aqui | la razon de haber intercalado en él mi primer | canto de la Amnistía. Animado del fervor que | ha debido este al público, he compuesto otros | tres, formando de los cuatro una especie | de poema separado, y me he servido á echarle | á volar por sí solo».

${ }^{28}$ Las sextinas que conformaban este mismo canto en La Amnistía eran 47. 
| Leon, está muy aumentado, y | variado de como se publicó | intercalar en Los Animales par-| lantes. (p. 3$)^{29}$.

En la página 56 hay una fe de erratas correspondientes a los dos primeros cantos y desde la página 57 hasta la 62 , se encuentra el apartado de notas finales ${ }^{30}$. Por último, este volumen nos proporcionará un dato más, dado que al final del cuarto canto de La Amnistía del León (p. 55) nos encontramos con un elemento paratextual que, a pesar de su brevedad, es altamente significativo: se indican el lugar y la fecha de la finalización del trabajo: «Fuente de Gabiluncia 10 de Agosto de 1822» que, como después veremos, será un dato importante para identificar al traductor que quería seguir siendo 'anónimo'.

\section{IDENTIFICACIÓN DEL TRADUCTOR}

Cuando emprendí la tarea de rastrear la posible autoría de esta traducción de los dos primeros cantos de Gli Animali parlanti todavía no conocía las dos versiones diferentes de La Amnistía y La Amnistía del León, puesto que no tenía constancia de que Menéndez Pelayo ni otros críticos las habían mencionado. Por otro lado, tratar de localizar a un personaje que se autodenominaba como «Cesante», en una época, además, en que los cesantes constituían un tipo social muy numeroso, era poco menos que una quimera ${ }^{31}$. La empresa me pareció tan sumamente complicada que decidí abandonarla por completo. Sin embargo, algún tiempo después, tuve conocimiento de estas dos versiones anteriormente citadas, que he podido consultar en la Biblioteca Nacional de España ${ }^{32}$; la aparición de las siglas «A.B.D.V.B.» en la segunda edición de este canto 'original' fue lo que me animó a rastrearlas retomando mis anteriores investigaciones. Fueran verdaderas o inventadas, al menos ya constituían una base por donde empezar a tratar de averiguar quién se escondía tras

29 En el ejemplar que se conserva en la BNE con signatura VE/697/33, la cuartilla correspondiente a las páginas 3 y 4, donde aparece la «Nota», ha sido arrancada. Para citarla, me sirvo del ejemplar conservado en la Biblioteca Menéndez Pelayo de Santander, con signatura 16257.

30 En total hay veinticuatro notas, que en este caso, aunque a veces aluden a cuestiones de los dos primeros cantos, no plantean observaciones relativas a aspectos teóricos de la traducción.

31 Aunque los diccionarios suelen definir al cesante como «empleado del gobierno que ha quedado sin empleo», su situación no era exactamente la de un desempleado, al menos en lo que respecta al plano jurídico. Su cese podía venir motivado por distintas causas: políticas, disciplinarias, por reducción de plazas, por conveniencias del servicio, etc. Tenían el derecho de percibir el «haber de cesantía», que era una especie de pensión, y además podían reingresar en su actividad según un sistema de turnos establecido en los Estatutos generales de la época. Para una mayor profundización en el 'tipo' social del cesante, véase el interesante artículo de Antonio Albuera Guirnaldos (1990), donde aborda esta figura típica del siglo XIX en sus diferentes variantes.

${ }^{32}$ Los datos se encuentran en el Proyecto Boscán o Catálogo histórico-crítico de las traducciones de obras literarias italianas al castellano y al catalán. Dicho catálogo se encuentra informatizado y está compilado bajo la dirección de Nieves Muñiz Muñiz y Cesáreo Calvo Rigual. Abarca desde el año 1400 hasta 1939, con información muy detallada y precisa relativa a las características y localización de estas traducciones, por lo que resulta de obligada consulta para quienes deseen profundizar en la influencia de la literatura italiana en España. Puede consultarse en línea: http://www.ub.edu/boscan/ 
ellas. A partir de aquel momento, suponiendo que «A.» o «A.B.» se correspondiesen con la inicial del nombre, me dispuse a elaborar listados de personas cuyo primer apellido empezase por las letras «B»o «D», que hubiesen vivido en esa época, que hubiesen estado relacionados con el ámbito literario o político y que, por diversos motivos, hubiesen cesado en su empleo.

Pronto aparecieron algunos personajes que por unas u otras circunstancias podrían ajustarse a los parámetros establecidos -recuérdese que la vuelta al trono de Fernando VII en 1814 supuso la expulsión de muchos funcionarios que, previamente, habían servido a José Bonaparte-, pero al final ninguno encajaba completamente con esas siglas. El número elevado de letras también me llevó a pensar que pudiera deberse a la presencia de nombres o apellidos compuestos o incluso a una fórmula que aúnase las iniciales de varias personas. Todas estas pesquisas y comprobaciones me llevaron muchísimo tiempo, con lo que la euforia inicial se tornó, con el paso del tiempo, en una total frustración.

El asunto quedó aparcado durante algún tiempo, hasta que un día, leyendo algunos materiales que había recopilado para la elaboración de otro trabajo, me topé con una obra del crítico italiano Camillo Ugoni (1856: 155), donde aseguraba que

il signor José Joaquin Viruez [sic] y Espinola, traduttore dell'Enriade di Voltaire, pubblicò pure in Madrid (1822) un saggio di traduzione spagnuola degli Animali parlanti. Sono soli i primi canti, aggiuntovene uno del traduttore intitolato L'Amnistia.

Bien es cierto que el tal Virués fue cesado de la carrera militar tras la vuelta al trono de Fernando VII en 1814, acusado de colaborar con el gobierno josefino, por lo que hubiera encajado como posible «Cesante», pero en 1822, fecha en la que el texto supuestamente se publicó, ya se habían iniciado los trámites necesarios para su rehabilitación política y militar. El caso es que como las iniciales de Virués tampoco coincidían con las que yo buscaba, ni siquiera alterando su orden, desde un principio sospeché que la afirmación de Ugoni era errónea, a pesar de que medio siglo después, en 1901, Ferruccio Bernini, en su Storia degli Animali parlanti di Giovan Battista Casti (Bernini 1901: 136), volvía a repetir lo mismo que ya había señalado Ugoni acerca de Virués ${ }^{33}$.

Por otro lado había datos que no me encajaban ya que en 1813, cuando la situación política española era mucho más convulsa, el diputado Rodríguez de Ledesma no había ocultado su identidad cuando tradujo Gli Animali parlanti y, que se sepa, no había recibido amonestación alguna a causa de su trabajo. Así que en 1822, coincidiendo con el pleno desarrollo del trienio liberal, donde existía la libertad de prensa, ¿qué razón podría llevar a alguien a ocultar su identidad si a priori no tenía necesidad de haberlo hecho? Pensé que para el ocultamiento existían fundamentalmente dos razones de peso: la primera tendría que ver con que el traductor anónimo hubie-

33 Desconozco de dónde pudo tomar Ugoni esta información, que como vemos, se difundió posteriormente sin tan siquiera llevar a cabo la más mínima comprobación acerca de la veracidad del dato. 
se sido 'díscolo' con respecto a la figura de Fernando VII durante los años anteriores, de 1808 a 1814, haciéndose notar en demasía y adoptando la postura de afrancesado, hasta el punto de que, pasados los años, siguiera teniendo desconfianza y miedo, a pesar de gozar de una amnistía; la segunda razón podría deberse a que nuestro 'enigmático cesante' fuese un eclesiástico que temiese represalias, puesto que la obra seguía estando prohibida por la Iglesia ${ }^{34}$ desde su inclusión en el Index librorum prohibitorum en 1805.

Pocas esperanzas tenía ya de lograr averiguar la identidad del Cesante y, tras varios intentos y largas jornadas de búsquedas infructuosas, incluso me di por vencido. Pero he aquí que, de nuevo, trabajando en el desarrollo de otra investigación y rastreando bibliografía que me pudiese resultar de utilidad, encontré un artículo publicado unas décadas atrás, cuyo tema giraba en torno a los impresos españoles en Francia, centrándose principalmente en el primer tercio del siglo XIX. Su autor es Robert Marrast, que en su curioso trabajo dice:

Otros datos interesantes nos proporcionan los documentos de los archivos. Por ejemplo, el 5 de julio de 1814, el prefecto de los Bajos Pirineos comunica lo siguiente al director general de la imprenta y la librería: el librero Cluzeau de Bayona le acaba de informar que se propone hacer imprimir una traducción anotada de Julia o la Nueva Heloísa de Rousseau, por cuenta de un canónigo español llamado Antero Benito y Núñez $z^{35}$. El documento es importantísimo, en primer lugar porque se trata de la primera edición francesa de la versión castellana de la novela de Rousseau, que en efecto salió en Bayona, impresa por Lamaignère (y no por Cluzeau, que era librero, es decir editor), en 4 tomos, sin el nombre del traductor, que así queda identificado, al menos en parte, ya que en la segunda edición, publicada en Burdeos en 1820 con título idéntico y algunas adiciones, el autor de las notas y de la versión castellana es designado bajo las iniciales A.B.V.B., cuyas primeras corresponden al del citado canónigo (Marrast 1981: 548).

La coincidencia de las primeras iniciales «A.B.», efectivamente, podían ser las de Antero Benito; pero ¿qué significaban las últimas «V.B.»? Podían tratarse de las iniciales de otra persona que hubiese colaborado conjuntamente en el trabajo, o incluso, haciendo nuevas suposiciones: la referencia a un oficio o cargo que desempeñase, o quizás -aunque de forma más remota- un título nobiliario, como por ejemplo 'Vizconde de B...'. Sin embargo, por si fuera poco, nuestro Cesante añadía entre ambos 'bloques' señalados por Marrast, otra inicial más: «A.B.D.V.B.». No hay duda de que el traductor o mejor, el autor de La Amnistía del León, quería ocultar su

\footnotetext{
${ }^{34}$ Recuérdese como el historiador de la Inquisición, Juan Antonio Llorente (1756-1823), en su Autobiografia (1982: 121-123), afirma que entre los meses de octubre de 1812 y julio de 1813, durante su estancia en Zaragoza, se entretuvo en traducir del italiano al español Gli Animali parlanti; pasados algunos años, reconocía que aún conservaba el manuscrito inédito y sin someterlo a una última revisión. Dada su condición de eclesiástico, esa traducción nunca vio la luz y, en caso de que se conserve, como ya se señaló, de momento tampoco hay noticias de su paradero.

${ }^{35}$ El autor del artículo coloca en este lugar una nota a pie de página, donde da cuenta de la ubicación de este dato: «Archives Nationales, París, F ${ }^{18} 19 \mathrm{CXV}$ ».
} 
identidad a conciencia, pero la aparición de la nueva pista me animó a volver a seguir con mis pesquisas.

En el Archivo Histórico Nacional llevé a cabo diversas investigaciones acerca de D. Antero Benito Núñez, que me proporcionaron valiosos datos. Había sido Canónigo Doctoral en la Catedral de Granada y Caballero de la Real y Distinguida Orden Española de Carlos $I I I^{36}$ desde 1803, nombramiento este último que no fácil de alcanzar, puesto que entre los diversos requisitos que se les exigían a los candidatos, estaba el de tener limpieza y pureza de sangre remontándose hasta sus bisabuelos. Los expedientes de estos Caballeros constituyen una riquísima fuente de información y en ellos se pueden consultar todos los datos personales de relevancia y cargos del Caballero hasta la fecha de su nombramiento, así como los relativos a sus antepasados.

El expediente núm. 1219, aprobado el 10-XII-1803, nos revela que D. Antero Benito Núñez ${ }^{37}$ había nacido en Ezcaray (La Rioja) el 3-I-1757 y, si continuamos indagando en la información que se nos ofrece acerca de sus antepasados, se ve claramente cómo nuestro Cesante ha construido el enigmático rompecabezas de las siglas: a su propio nombre «A.B.» une las iniciales de los apellidos de sus abuelos: la «V.» del segundo apellido de su abuelo paterno y «B.» del primer apellido la abuela materna ${ }^{38}$. El abuelo paterno se apellidaba Benito del Valle, mientras que la abuela materna Barrenechea. Así, desarrollando las iniciales, compondríamos el nombre ficticio de Antero Benito del Valle Barrenechea, que lógicamente coincide con las citadas iniciales A.B.D.V.B. ${ }^{39}$.

36 Tradicionalmente, gran parte de estos personajes de cierta relevancia intelectual y política, nobiliaria o con arraigo dentro de la Iglesia, como en este caso, aspiraban a poder ingresar en una Orden militar, en la que desempeñaban el cargo de Caballeros. De este modo disfrutaban, además de un elevado prestigio social, de una serie de concesiones y privilegios. La Real y Distinguida Orden Española de Carlos III fue establecida por el Monarca en 1771 con la finalidad de condecorar a aquellas personas que se hubiesen destacado especialmente por sus buenas acciones en beneficio de España y la Corona. Aunque en sus inicios se encontraba dentro de la categoría de las Órdenes Militares, en 1847 formalmente se convirtió en orden civil. Desde su creación, sigue siendo la condecoración civil de mayor distinción que puede otorgarse en España.

${ }^{37}$ En el actual catálogo del Archivo Histórico Nacional, el nombre de 'nuestro' Caballero aparece reflejado erróneamente. El expediente núm. 1219 se identifica con «Antonio» en vez de «Antero», quizá por algún error de lectura, que puede justificarse en que la grafía manuscrita de la portadilla no se lee con facilidad y tampoco el nombre «Antero» es tan común como para identificarlo de inmediato. El mismo error aparecía ya en el Índice de pruebas de los caballeros de la Real y Distinguida Orden española de Carlos III desde su institución hasta el año 1847 de Vicente Vignau y Ballester (1904: 25) y también en la magnífica obra de Vicente de Cadenas y Vicent, titulada Extracto de los expedientes de la Orden de Carlos $3^{\circ}, 1771$ 1847 (1981, II: 68). En relación con esta última obra, y sin que este apunte sirva para mermar un ápice su gran valía, quiero añadir que también aparece equivocada la fecha de nacimiento, que en este caso se confunde con la del bautismo (22-I-1757).

${ }^{38}$ Resulta al menos curioso que adopte la combinación de los apellidos 'del padre del padre' y de 'la madre de la madre'. Del abuelo paterno resulta obvio que tome el segundo apellido, puesto que el primero ya lo comparte por descendencia directa; por otra parte, la elección del apellido de la abuela materna en detrimento de la abuela paterna no suponemos que tenga que ver con el afecto o cariño personal, puesto que según consta en el citado Expediente 1219 del AHN (fols. 43v-44r), ambas habían fallecido incluso antes de casarse los padres de D. Antero.

39 En este conjunto de iniciales, la «D.» intermedia que antecede a la «V.» no creo que aluda al cargo de Doctoral, en el que ya había cesado en 1812, sino al apellido del Valle (D.V.). 
Aclarado el enigma, para rastrear los datos referentes a la etapa de D. Antero como Canónigo Doctoral en la Catedral de Granada, me he servido de la información recogida en el trabajo de María Dolores Tortosa Linde (1989), en el que labra un completo perfil biográfico del personaje desde su llegada a Granada en 1772 hasta su huida en $1812^{40}$ por miedo a las represalias al haber colaborado con el gobierno josefino. Ya el 15 de agosto de 1810, con motivo del cumpleaños y del enlace de Napoleón con la Emperatriz María Luisa, D. Antero había hecho una Oración en la Misa solemne celebrada en la Catedral, donde exponía los beneficios que había traído a España la llegada de Napoleón ${ }^{41}$. La segunda prueba de su afrancesamiento llega con la publicación en 1811 de una obra de teatro titulada Calzones en Alcolea: Tragicomedia, dividida en tres actos y estrenada en Sevilla, que muestra el proceso de rendición y sumisión de la localidad de Alcolea a los franceses, hecho que obviamente apoya el autor ${ }^{42}$. La obra teatral constituye una sátira despiadada contra los guerrilleros españoles que, retratados como simples bandoleros, luchan contra las tropas francesas y contra los afrancesados, que se presentan como los auténticos defensores de la patria.

En el Cabildo celebrado el 15 de septiembre de 1815 (Tortosa Linde 1989: 353) se comunica que D. Antero Benito Núñez ha salido de la ciudad de Granada, cesado de su cargo, que queda vacante. Así lo atestigua una nota manuscrita, añadida en la portada del ejemplar de la citada Oración que se cita en la bibliografía:

Quando las tropas Españolas desalojaron a las Francesas de esta ciudad de Granada, y continuaron bencedoras [sic] hasta destronar a Napoleon, se fue con las tropas francesas este Doctoral quien perdio su empleo y quedó viviendo en Francia reducido a miseria.

Tras su cese, el canónigo Antero Benito se trasladó a Bayona y allí permaneció hasta marzo de 1816, fecha en que decidió volver a España. El Cónsul español en la ciudad francesa, Juan Antonio Iparraguirre, informó al Ministro Pedro Cevallos de su regreso, afirmando que «este sacerdote no ha tenido el mejor concepto tanto por su conducta bastante inmoral como por sus opiniones» (López Tabar 2001: 166n).

40 Afirma Tortosa Linde (1989: 351) que «el último día que asistió este Doctoral al Cabildo fue el 29 de agosto de $1812 »$.

${ }^{41}$ ORACIÓN | RECITADA EN LA CATEDRAL DE GRANADA | EL DÍA 15 DE AGOSTO DE 1810. | POR | DON ANTERO BENITO Y NÚNEEZ. | Canónigo Doctoral de la misma. | CON MOTIVO DE LA SOLEMNE FUNCIÓN | del cumpleaños de S.M.I. y R. el | Emperador Napoleón, y su enlace con | S.M.I. y R. la Emperatriz María Luisa. | GRANADA: | EN LA IMPRENTA DE FRANCISCO GÓMEZ ESPINOSA | DE LOS MONTEROS. [s.f. pero 1810].

${ }^{42}$ Se trata de la localidad almeriense de Alcolea, colindante con la provincia de Granada. El impreso teatral no va firmado ni aparece el nombre del impresor, aunque va precedido de una nota dedicatoria firmada, esta vez, con las siglas A.B.N, que en este caso coinciden con las de su verdadero nombre: Antero Benito Núñez. El éxito de la obra debió ser notable, por lo que en el mismo año aparece una segunda edición aumentada, en la que se incluye nuevamente la Oración leída en la Catedral -también en francés- y, además, unos versos del mismo Antero Benito para conmemorar el nacimiento del Príncipe de Francia, Rey de Roma, que se celebró en Granada con un magnífico banquete el 8 de noviembre de 1811 (Tortosa Linde 1989: 348-349). 
Por tanto, con lo dicho hasta aquí, he tratado de demostrar que ese 'ignoto' «Cesante» que tradujo los dos primeros cantos de Gli Animali parlanti de Casti, a los que añadió otro canto de 'cosecha propia' y que posteriormente lo aumentó para convertirlo en La Amnistía del León, no es otro que Antero Benito Núñez, Doctoral de la Catedral de Granada.

Y ya para finalizar, por si todavía quedase alguna duda, me permito aportar una prueba más que sirva para aclarar el misterio: ¿recuerdan la Fuente de Gabiluncia que aparecía al final de La Amnistía del León? Se trata de un topónimo de Ezcaray ${ }^{43}$, la localidad donde había nacido don Antero, un curioso literato que tradujo obras prohibidas ${ }^{44}$ y por su condición de eclesiástico - aunque cesado de su cargo- trató de ocultar su identidad.

\section{REFERENCIAS BIBLIOGRÁFICAS}

Albuera Guirnaldos, Antonio (1990): «El cesante: análisis de un "tipo" social del siglo XIX», Cuadernos de historia contemporánea 12, pp. 45-66.

ArCE, Ángeles (2009): «Casti, Giambattista» en Francisco Lafarga y Luis Pegenaute (eds.), Diccionario histórico de la traducción en España, Madrid, Gredos, pp. 186-187.

ArChivo Histórico Nacional (AHN) (1803): Sección Estado, Orden de Carlos III, [Expediente] $1219 \mid$ Pruebas de D. ${ }^{\mathrm{n}}$ Antero Benito Núñez | Aprovadas en 10 de Diz. ${ }^{\text {bre }}$ de 1803.

ArReguI, Santiago (1958): «Toponimia de Ezcaray», Euskera: Trabajos y actas de la Academia de la Lengua Vasca III, pp. 83-102.

BeNITo NúÑEZ, Antero (s.f. [1810]): Oración recitada en la Catedral de Granada el día 15 de agosto de 1810. Por don Antero Benito y Núnez. Canónigo Doctoral de la misma. Con

43 Al final de La Amnistía del León, encontrábamos una fecha y un lugar de composición: «Fuente de Gabiluncia 10 de Agosto de 1822». Una vez conocido el lugar de nacimiento de D. Antero por el expediente del Archivo Histórico Nacional, localicé un trabajo de Santiago Arregui (1958: 83-102) que versa sobre la toponimia de la localidad riojana de Ezcaray. Cuál fue mi sorpresa cuando encontré el término «Gabiluncia (Loma de)» (Arregui 1958: 94). El artículo incluye un mapa confeccionado a mano (Arregui 1958: 90) en el que se sitúa el paraje muy cerca de dicha localidad, aunque no encontré mención alguna a la fuente citada por Antero Benito. Por ello, me dirigí al Ayuntamiento de Ezcaray solicitando ayuda para confirmar la existencia del lugar y su posible localización. Agradezco enormemente a D. Jorge Matey Valderrama, Técnico del área medioambiental del Ayuntamiento de Ezcaray, la desinteresada ayuda que me prestó, pues me confirmó que antaño existía una «Fuente de Gabiluncia», de la que hoy, como consecuencia del deterioro producido por el desuso, apenas queda el manantial que la nutría. Estaba situada al pie de la vaguada del mismo nombre, próxima al camino que sube hacia la aldea -hoy despoblada- de Cilbarrena, a unos veinte minutos caminando desde Ezcaray; las coordenadas geográficas de localización son: Latitud $42^{\circ} 18^{\prime} 34,75^{\prime}$ " N / Longitud $3^{\circ} 0^{\prime} 19,03^{\prime}$ 'W. Se trata de un lugar tranquilo, alejado de miradas curiosas y muy soleado, condición esta última que se agradece, sobre todo por enclavarse este territorio en una zona montañosa de clima frío. Este entorno natural tan propicio, además de su verano fresco, bien pudieron ayudar a D. Antero para llevar a cabo, si no todo el trabajo de traducción y composición propia, al menos, esta última versión de La Amnistía del León en la que, como dijimos, imita a Casti.

44 Recordemos que además de llevar a cabo la traducción de Gli Animali parlanti de Casti, Antero Benito Núñez tradujo y publicó en Francia la novela Héloise de Rousseau, primero de forma anónima y posteriormente añadiendo las iniciales «A.B.V.B.» en la segunda edición, según nos había señalado Robert Marrast (1981: 548). Ambas obras estaban incluidas en el Index librorum prohibitorum en 1805 (decreto del 26 de agosto) y 1806 (decreto del 9 de diciembre) respectivamente. 
motivo de la solemne función del cumpleaños de S.M.I. y R. el Emperador Napoleón, y su enlace con S.M.I. y R. la Emperatriz María Luisa. Granada: en la Imprenta de Francisco Gómez Espinosa de los Monteros. [Biblioteca de la Universidad de Granada. Signatura BHC/C-019-052(1)].

Bernini, Ferruccio (1901): Storia degli 'Animali Parlanti' di Giovan Battista Casti, Bologna: Ditta N. Zanichelli.

CAdENAS Y Vicent, Vicente de (1981): «Antonio [sic] Benito y Núñez Hurtado de Mendoza y Barrenechea», en Extracto de los expedientes de la Orden de Carlos III, 1771-1847, vol. II, Madrid, Hidalguía, pp. 68-69.

CANTÙ, Cesare (1852): Historia de cien años 1750-1850, escrita en italiano por César Cantú, y traducida de la segunda edición, anotada y precedida de un prólogo, por don Salvador Costanzo, Madrid, Establecimiento Tipográfico de Mellado.

Casti, Giambattista (1797): Il Poema tartaro, Italia [Milano], [s. i.].

Casti, Giambattista (1801-1802: Anno IX): Novelle, Parigi, Typografia Italiana.

Casti, Giambattista (1802: Anno X): Gli Animali parlanti, Parigi, Treuttel e Würtz.

Cesante, Un (1822a): Los Animales parlantes de Casti: En el mismo género y número de versos españoles que el original italiano / Por un cesante; Madrid, Imprenta Calle de la Greda, por su regente D. Cosme Martínez.

Cesante, Un (1822b): Segundo Canto de los Animales parlantes: En el mismo género y número de versos españoles que el original italiano. Madrid, Imprenta Calle de la Greda, por su regente D. Cosme Martínez.

Cesante, Un (1822c): La Amnistía: canto tercero de Los Animales parlantes, intercalar y original del autor de los dos primeros; Madrid, Imprenta calle de la Greda, por su regente D. Cosme Martínez, pp. 108-117.

Cesante, Un [A.B.D.V.B.] (1823): La Amnistía del León: poema dividido en cuatro cantos, por A.B.D.V.B. Madrid, Imprenta calle de la Greda, por su regente D. Cosme Martínez.

Diario de Madrid (14-VII-1805): «[Listado de libros] prohibidos aun para los que tienen licencia», p. 57.

El Censor: Periódico político y literario (1822a), tomo XVI, n. 93, 11-V-1822, Madrid, Imprenta de D. León Amariti, Plazuela de Santiago, n. ${ }^{\circ}$ 1, p. 240.

El Censor: Periódico político y literario (1822b), tomo XVII, n. 98, 15-VI-1822, Madrid, Imprenta de D. León Amariti, Plazuela de Santiago, n. ${ }^{\circ}$ 1, p. 160.

Estelrich, Juan Luis (1889): Antología de poetas líricos italianos, Palma de Mallorca, Escuela-Tipográfica Provincial.

Index librorum prohibitorum (1838): Mechliniæ, P. J. Hanicq.

LÓPEZ TABAR, Juan (2001): Los famosos traidores. Los afrancesados durante la crisis del Antiguo Régimen (1808-1833), Madrid, Biblioteca Nueva.

LloreNTE, Juan Antonio (1982): Noticia biográfica (Autobiografia), con una «Nota crítica» de Antonio Márquez y un «Ensayo bibliográfico» por Emil van der Vekene, Madrid, Taurus.

MARRAST, Robert (1981): «Impresos españoles en Francia: Método y primeros resultados de investigación», en S. Castillo et al. (eds.), Estudios de Historia de España: Homenaje a Manuel Tuñón de Lara, vol. II, Madrid, Universidad Internacional Menéndez Pelayo, pp. 543-552.

MenÉndeZ y Pelayo, Marcelino (1982): «Carta 255: A Gumersindo Laverde, Madrid, 12 de octubre de 1875», en Epistolario, vol. I, Madrid, Fundación Universitaria Española, pp. 334-335.

MuÑIz MuÑIz, María de las Nieves (2003): «Sulle prime traduzioni spagnole degli Animali Parlanti di Casti», Esperienze letterarie XXX: 3-4, Roma-Pisa, Istituti Editoriali e Poligrafici Internazionali, pp. 227-250. 
MuÑIz MuÑIz, María de las Nieves (2005): «Milà i Fontanals traductor clandestí de Casti», Els Marges. Revista de llengua i literatura 76, pp. 69-78.

Parenti, Marino (1951): Dizionario di luoghi di stampa falsi, inventati o supposti in opere di autori e traduttori italiani, Roma, Sansoni Antiquariato.

TorTosa Linde, María Dolores (1989): «Un escritor olvidado amigo de Porcel: Don Antero Benito y Núñez», en C. Argente del Castillo et al. (eds.), Homenaje al Profesor Antonio Gallego Morell, vol. III, Granada, Universidad de Granada, pp. 341-357.

UGoni, Camilo (1856): Della letteratura italiana nella seconda metà del secolo XVIII. Opera postuma di Camillo Ugoni, vol. I, Milano, Tipografia di Giuseppe Bernardoni di Gio.

VignaU y BAllester, Vicente (1904): Índice de pruebas de los caballeros de la Real y Distinguida Orden española de Carlos III desde su institución hasta el año 1847, Madrid, Archivo Histórico Nacional y Tipografía de la Revista de Archivos, Bibliotecas y Museos. 